\title{
Spectral Characteristics of Soybean during the Vegetative Cycle Using Landsat 5/TM Images in The Western Paraná, Brazil
}

\author{
Erivelto Mercante ${ }^{1}$, Rubens A. C. Lamparelli², \\ Miguel A. Uribe-Opazo ${ }^{1}$ and Jansle Viera Rocha ${ }^{2}$ \\ ${ }^{1}$ Western Paraná State University (Unioeste-PR) \\ ${ }^{2}$ State University of Campinas (Unicamp-SP) \\ Brazil
}

\section{Introduction}

There are many attempts of using alternative tools capable of providing more reliable and specific information in relation to agricultural crops. Techniques linked to remote sensing appear as high potential instrumental. The spectral-temporal profiles of crops can establish the growing standard and their development degree during the phenological cycle, because structural changes are progressive with time and result in corresponding changes in the spectral reflectance. These changes occurred in the curves particular to the spectral profiles of a specific crop so may be associated to their condition (development) and also to their efficiency.

The crop monitoring by use of the spectral-temporal profile demands the atmospheric correction of the images so that it becomes possible to analyze the information under the same response unit, which means surface reflectance (Du et. al., 2002).

The study of Chander \& Markham (2003) shows the development of a procedure to improve the TM sensor calibration, offering Landsat 5/TM data users, methods and parameters to convert image digital numbers (DNs) to useful data, such as spectral radiance, top-ofatmosphere reflectance (apparent) and temperature estimates.

The correction can be performed in two different ways: by models of radiative transfer like Modtran2 (Anderson et al., 1993), Scoradis based on the 5S (Zullo Jr, 1994) and 6S (Vermote et al., 1997), where atmosphere information is required in order to estimate the absorption and scattering effects. Another method takes into account the subtraction of grey levels of dark pixels (DOS- Dark Object Subtraction). This method has the advantage of not depending on atmospheric parameters (Teillet, 1995). Both procedures are considered absolute corrections.

Researchers are working on the relative correction of images to avoid the gathering of data that feed the radiative transfer and atmospheric correction models, which are too slow and expensive to be acquired. These methods assume that the relation of the top-of-atmosphere radiation recorded in two different dates, from regions with constant reflectance, is especially homogeneous and may be approximated by a linear function (El Hajj, 2008). 
The relative calibration, also referred to as image normalization (Schroeder et al., 2006) is applied by pairs of images radiometrically related using methods of choice of pseudoinvariant pixels - PIFs (Hall et al., 1991; Schott et al. 1988). Another method of automatic treatment of temporal series was presented by Nielsen et al. (1990), who determine invariant pixels by using the canonical correlation (CCA), also called MAD (Multivariate Alteration Detection), to find the linear combination between two groups of variables (spectral bands of the result image and reference image) ordered by correlation or similarity between pairs. The MAD technique was successfully used by Canty et al., (2004), who performed the radiometric normalization of multitemporal series of images from Landsat 5/TM, Landsat 7/ETM+ and Spot HRV satellites. The authors compared the results obtained by the MAD with those obtained with the manual way of detecting invariant pixels. The results were favorable to the MAD technique in relation to the time it took to obtain the invariant pixels in extensive areas.

Canty et al. (2004) used, along with the MAD technique, the orthogonal regression instead of the linear regression (generally used), to accomplish the normalization of the obtained images in different dates. The results gathered from the orthogonal regression proved to be more satisfactory, in the sense of being able to keep the radiometric resolution of the images after normalization, in other words, it did not distort the typical behavior of the present targets in the images used for the normalization, in each one of the bands of the satellite. It is noteworthy the fact that it preserved the radiometric resolution of the images after normalization, what was very much emphasized in the study of Du et al. (2002).

Agricultural crop monitoring by satellite images makes use of vegetation indexes, defined as combinations of spectral data of two or more bands (Moreira, 2000). Among several vegetation indexes available, the NDVI (Normalized Difference Vegetation Index, Rouse et al., 1973) has been largely used. Crist (1985) appoints the importance of the use of the indexes resulting from the orthogonal transformation Tasseled Cap. These indexes use the six non-thermal bands of the TM sensor and attribute different weights for each one of them by linear equations. As a result, three synthesis-images are generated: "brightness", "greenness" and "wetness". The image "greenness", or the vegetation index GVI (Greenness Vegetation Index), is created from the TM sensor of the Landsat 5 satellite.

\section{Objective}

The main goal of this study was to analyse changes in the spectral behavior of the soybean crop, during the vegetative cycle, by spectral-temporal profiles of the mapped crop areas, using the vegetation indexes NDVI e GVI (Greenness Vegetation Index) of multispectral images from the Landsat 5/TM satellite.

\section{Methodology}

Figure 1 shows the area coverage of the image and the localization of the 36 municipalities which were monitored in this study. A commercial agricultural area was also monitored, it is located next to the municipality of Cascavel, with approximately 57ha and central coordinates of latitude $24^{\circ} 57^{\prime} 30^{\prime \prime} \mathrm{S}$ and longitude $53^{\circ} 34^{\prime} 20^{\prime \prime} \mathrm{W}$ and average altitude of 650 meters.

The climate in the region is presented as temperate mesothermal and superhumid, climate type Cfa - Köeppen, with moderate temperatures, well distributed rains and hot summer. In 


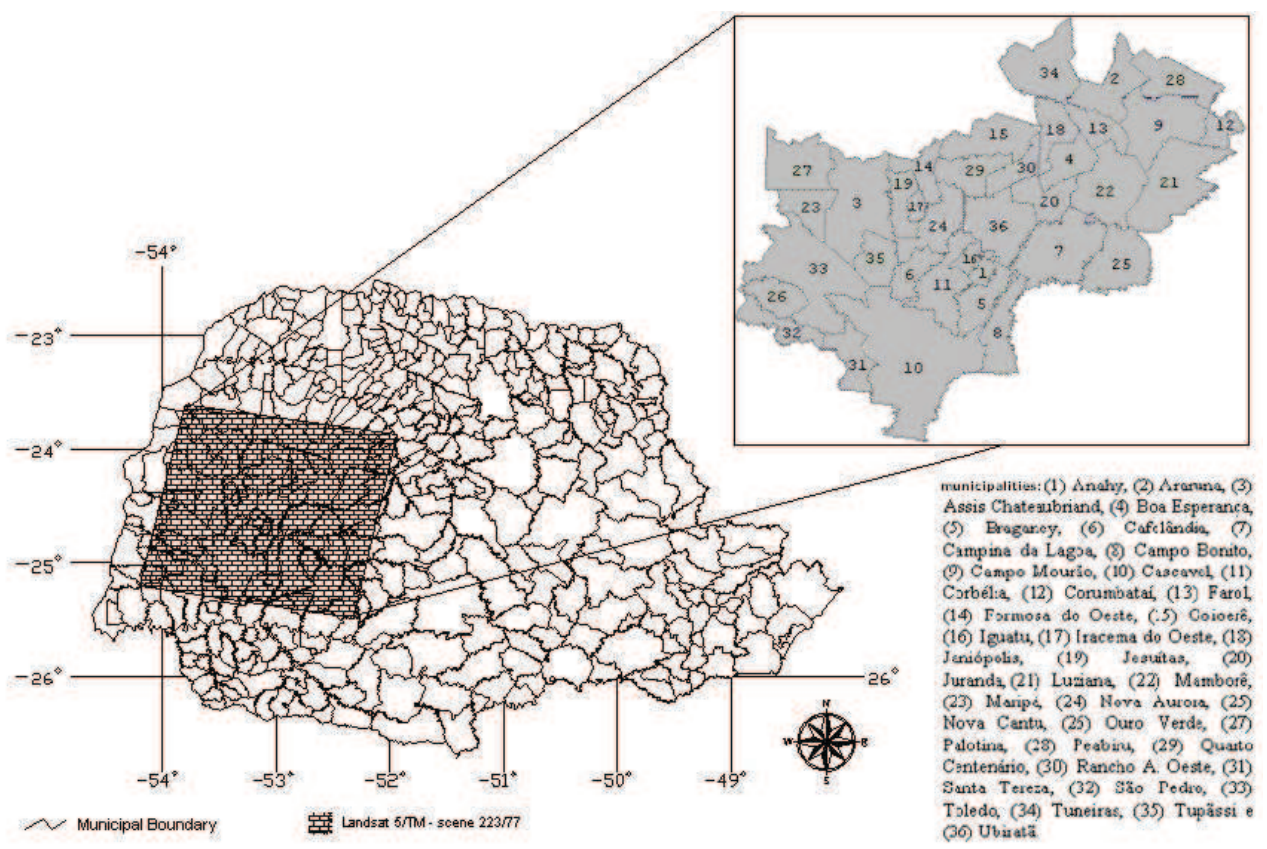

Fig. 1. Location of the Landsat 5/TM Path/Row 223/77 in Parana State, Brazil, with the location of the 36 municipalities monitored.

the Winter months, the average temperature is lower than $16^{\circ} \mathrm{C}$ and in the Summer months the maximum temperatures overcome $30^{\circ} \mathrm{C}$, and an annual average temperature of $21^{\circ} \mathrm{C}$. The region is subjected to frost, although it is not frequent. The soil in the monitored area with approximately 57ha is classified as Dystroferric Oxisol, and the soybean variety cultivated was the Coodetec 216 (CD 216), characterized as part of the early maturation group, and an average total cycle of 112 days (Coodetec, 2007).

The TM/Landsat 5 (Thematic Mapper) images were obtained at the Instituto Nacional de Pesquisas Espaciais (INPE) - (National Institute for Space Research) with the L1g correction level and also the relative calibration using the CCRS-CPF (Canada Centre of Remote Sensing - Calibration Parameter File) coefficient for all images, assuring the same procedures of relative calibration to them.

The softwares IDRISI Kilimanjaro (Eastman, 2003), Envi 4.0 (Sulsoft, 2006) and SCORADIS based on the 5S (Zullo Jr., 1994) were used at the processing and analysis of the Landsat 5/TM images. The crop monitoring was performed by means of selected images in order to cover all the soybean crop cycle development periods in the region (emergency, flowering and vegetative peak) in the dates (harvest 2004/2005): november 11, 2004; december 09, 2004; december 25, 2004; january 26, 2005 and february 11, 2005.

The transformation or radiometric calibration aims mainly at the reduction of distortions caused by sensor discrepancies. It is performed when there is a need of converting the signal which is captured by the sensor, in target radiance or reflectance, so that the image data can be related to measurements accomplished at the targets on the earth surface.

The flowchart on Figure 2 shows these procedures: 


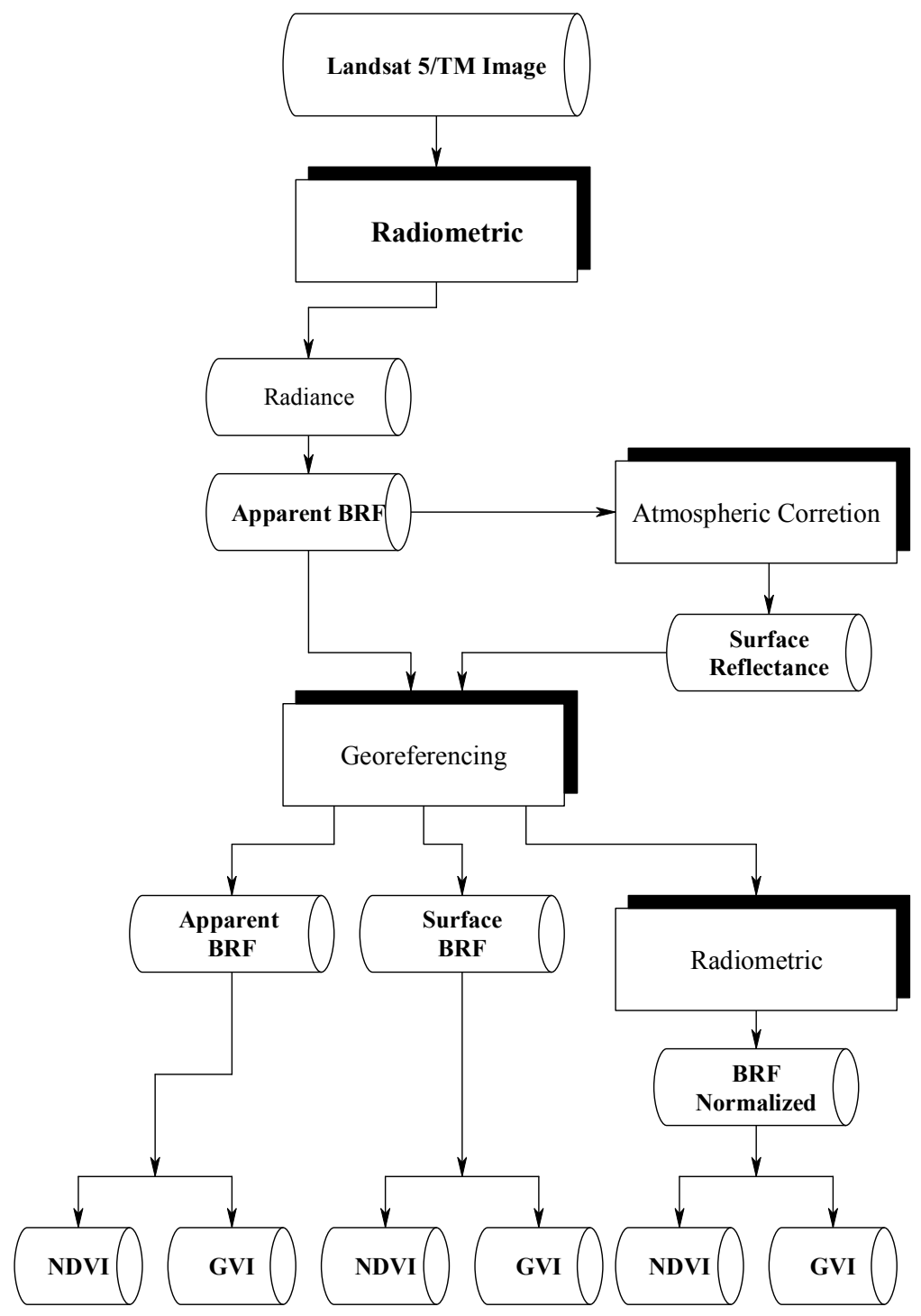

Fig. 2. Flowchart with image processing stages.

The first step performed was the conversion of the Digital Number (DN) into radiance values. Next, the radiance data were transformed into Bi-directional Reflectance Factor BRF apparent (BRFa- top-of-atmosphere). These procedures were accomplished according to Chander and Markham (2003). The conversion of the digital numbers in radiance values was performed by means of post-calibration parameters of the TM sensor, such as minimum radiance $\left(L M I N_{\lambda}\right)$ and maximum radiance $\left(L M A X_{\lambda}\right)$, listed values for each band of the Landsat 5/TM. The conversion was performed according to Equation 1. 


$$
L_{\lambda}=\left(\frac{L M A X_{\lambda}-L M I N_{\lambda}}{Q_{c a l \max }}\right) \times Q_{c a l}+L M I N_{\lambda}
$$

Wherein:

$L_{\lambda}$ : spectral apparent bi-directional radiance in $\mathrm{W} .\left(\mathrm{cm}^{2} . \mathrm{sr} . \mu \mathrm{m}\right)^{-1}$;

Qcal : pixel value in digital number (DN);

Qcalmax : maximum digital number (DN);

$Q$ calmin: minimum digital number $(\mathrm{DN})$;

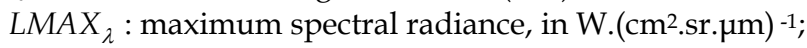

$\operatorname{LMIN}_{\lambda}$ : minimum spectral radiance, in W.(cm².sr. $\left.\mu \mathrm{m}\right)^{-1}$.

The radiance values were transformed into Bi-directional Reflectance Factor - BRFa by means of the values of the solar zenith angle $\left(\theta_{s}\right)$, distance earth-sun $(d)$ and by the average spectral irradiance of the Sun on top-of-atmosphere - $\operatorname{ESUN}_{\lambda}$ (listed), according to Equation 2.

$$
\rho_{P}=\frac{\Pi \cdot L_{\lambda} \cdot d^{2}}{\operatorname{ESUN}_{\lambda} \cdot \cos \theta_{s}}
$$

Wherein:

$\rho_{P}: \mathrm{BRFa} ;$

$\pi$ : value/amount 3,141516

$L_{\lambda}:$ spectral radiance, in W.(cm².sr. $\left.\mu \mathrm{m}\right)^{-1}$;

$d$ : sun-earth distance, in astronomic units;

$\operatorname{ESUN}_{\lambda}$ :mean spectral irradiance from the sun at the top of the atmosphere, W.(cm².sr. $\left.\left.\mu \mathrm{m}\right)\right)^{-1}$;

$\theta_{s}$ : solar zenith angle.

The TM sensor images were corrected to the atmosphere effect by using the SCORADIS software. In order to execute the correction algorithm, the following input data was necessary: geographic location (Latitude and Longitude); date and time of the satellite pass; type and quantity of present aerosols; atmospheric model of the gaseous components, mainly water vapor and ozone. The output data is the surface BRF (BRFs). The necessary parameters for the atmospheric correction procedure were aerosols optical thickness, water vapor content $\left(\mathrm{g} \mathrm{cm}^{-2}\right)$ and ozone layer thickness $\left(\mathrm{cm} \mathrm{atm}^{-1}\right)$. They were obtained by MODIS images (MOD04_L2: MODIS Level 2 Aerosol over Land and Ocean Product) which has atmospheric parameters. These images were processed on the Envi 4.0 (Sulsoft, 2006) software. The satellite TERRA/MODIS pass time was close to (difference of minutes) the Landsat 5/TM pass, a determinant factor, once the atmospheric conditions have a great variation in time. The atmospheric attributes values were calculated from the arithmetic average of all valid pixels, which were found at the coverage area of the scene 223/077 of the TM sensor (Table 1).

After the transformations and corrections performed above, the images were georeferenced and transformed into the latitude and logitude, Datum WGS84 coordinate geographical.

The normalization of the images was performed adopting the method proposed by Canty et al. (2004), which must approximate the values of average and variance of each one of the TM image bands in the normalized, average and variance images of the reference image, not discarding, obviously, the spectral evolution, at the time of the original targets of the studied 


\begin{tabular}{cccc}
\hline Satellite Pass & $\begin{array}{c}\text { Optical Thickness of } \\
\text { the Aerosols }\end{array}$ & Water vapor $\left(\mathbf{g ~ c m}^{-2}\right)$ & Ozone $\left(\mathbf{c m ~}_{\mathbf{~ a t m}} \mathbf{- 1}\right)$ \\
\hline November 23, 2004 & 0.057 & 3.229 & 0.283 \\
December 9, 2004 & 0.163 & 2.802 & 0.277 \\
December 25, 2004 & 0.086 & 2.500 & 0.272 \\
January 26, 2005 & 0.071 & 3.803 & 0.262 \\
February 11, 2005 & 0.125 & 2.233 & 0.406 \\
\hline
\end{tabular}

Table 1. Atmospheric parameters taken from the MODIS images

image. The image of november 23, 2004 was used as reference to the application of the method on images taken in other dates (target calls), obtaining the normalized BRF (BRFn) values at the end.

Supervised classification of the TM images, using the MaxVer algorithm, was carried out to map and estimate areas occupied with soybean throughout the cropping season. At the end of this procedure, the synthesis image was obtained containing the area occupied by the crop. This image was obtained by adding up, by using the boolean operation OU (OR), the result of the classification found in each image, called soybean mask (Mercante et al., 2010). In order to distinguish the spectral response of the soybean crop biomass, in the 36 monitored municipalities, the vegetation indexes of two different approaches were used: one based on bands ratio, which is the NDVI index - Normalized Difference Vegetation Index (Rouse et al., 1973) and another based on spectral transformation, Tasseled Cap (Brightness, Greenness e Wetness) originally proposed by Kauth and Thomas (1976), in which the component "Greenness", called GVI index - Green Vegetation Index, uses the six non-thermal bands of the Landsat 5/TM or Landsat 7/ETM+ satellites, further assigning different weights for each one of them by linear transformations.

The spectral data extraction of the NDVI e GVI in each municipality, of the 36 monitored, was performed by the municipal average of the spectral response contained in the pixels classified as soybean (soybean mask of each studied municipality). Only the pixels which were found completely inside the municipality limits (IBGE, 2001) were computed, and also only those which were not contaminated by clouds (Mercante, 2007). Thus, only the spectral behavior of the NDVI and GVI indexes was obtained, what is typical of the soybean crop for each studied municipality.

In the 57 ha area, the spectral data extraction was performed by using a sampling grid, removing the spectral value of the pixel in which the coordinate of the sampled place was located. This was performed in order to gather data of the "pure pixels", in other words, data that could express only the spectral behavior of the soybean crop (Mercante et al., 2009). A regular sampling grid with 100 points, spaced by 75 meters, was used, as shown in Figure 3. Posteriorly, the sampling points which were found at the surround plot were disconsidered, in other words, those under, at least partial, influence, of other crops or roads that circle the area. Also, the sampling elements contaminated with clouds were eliminated, so there was, for each image data, a variable number of computed pixels. Descriptive statistical analysis of the values of vegetation indexes NDVI and GVI of all images were performed, in order to characterize the different spectral values calculated considering BRFa, BRFs and BRFn. The statistical normality tests Anderson-Darling and $\mathrm{T}$ test of average comparison, in the analysis of the results, were accomplished the level of $5 \%$ of significance. 


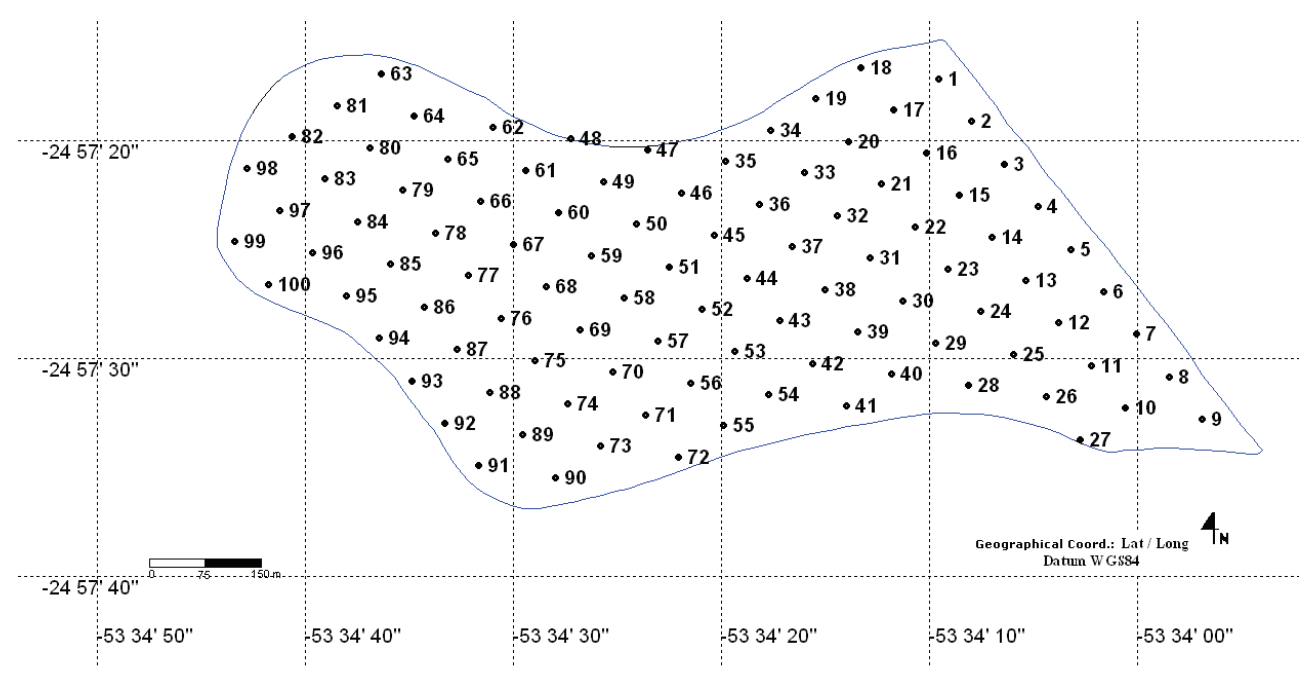

Fig. 3. Systematic sampling schedule of spectral data in the monitored area.

\section{Results and discussions}

To the characterization of the spectral behavior of soybean in the 57 ha area, expressed in the images of the BRFa, BRFs and BRFn, graphics were created containing the BRF values in each band (wavelength intervals), Figure 4 . After achieving the atmospheric correction in all five images, the image of november 23, 2004 was used as reference image in the normalization process. Thus, as this image does not have normalized BRF values, the reason for its choice is that it is totally without interference of clouds and has good visual quality.

As it is possible to observe in the graphs (Figure 4), to perform the validation of the atmospheric correction and normalization techniques, comparisons were performed with the spectral behavior typical of the soybean crop. One can see that the atmosphere correction and normalization techniques did not mischaracterize the typical spectral behavior of the soybean crop in the five processed images.

The atmospheric correction and normalization by band coherences were verified in each image. It is expected that in the visible bands (bands 1, 2 and 3) there is a decrease in the BRF values, due to molecular scattering, while for the infra-red bands (bands 4,5 and 6) an increase is expected in the BRF according to the correction, mostly in water vapor (Zullo JR., 1994). Figure 4 shows that the method of atmospheric correction and the normalization of images corrected the scattering effects of bands 1, 2 and 3 in all dates, what decrease the BRF value, when they are compared to the apparent values of BRF. A compensation becomes clear in these images, or a gain in BRF in band 4, therefore easing the absorption effect by gases (which decreases the BRF values on this band), according to Vermote et al. (1997). One can see, also, both for the atmospheric correction data and the normalization, a coherence in relation to the behavior of the visible bands - band 1 (blue), band 2 (green) and band 3 (red), over the target, in which predominates the great absorption of energy on the bands 1 and 3 , and a light scattering in band 2. 
November 23, 2004

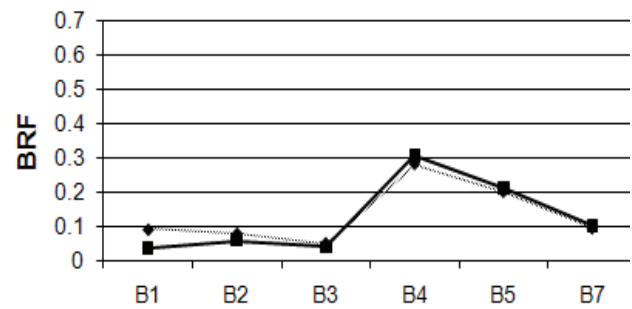

December 25, 2004

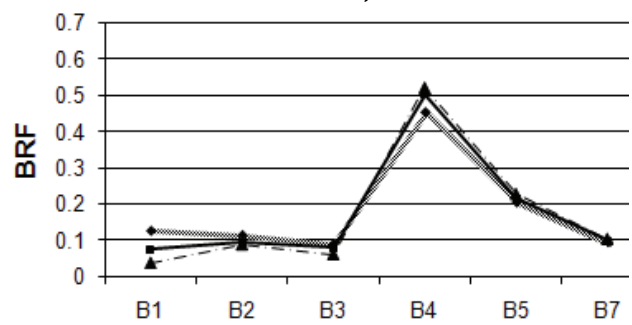

February 11, 2005

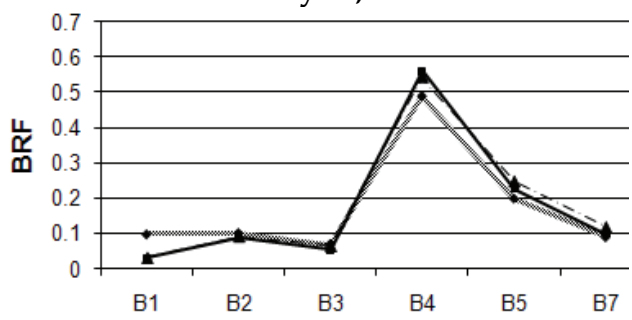

December 09, 2004

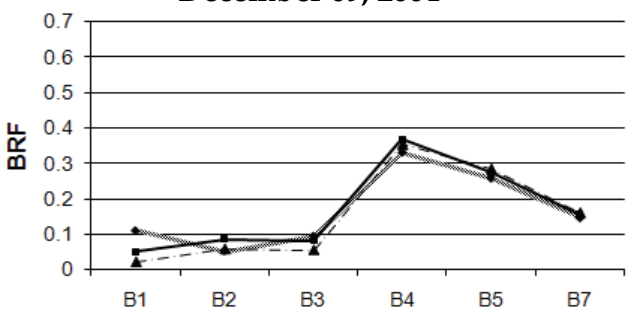

January 26, 2005

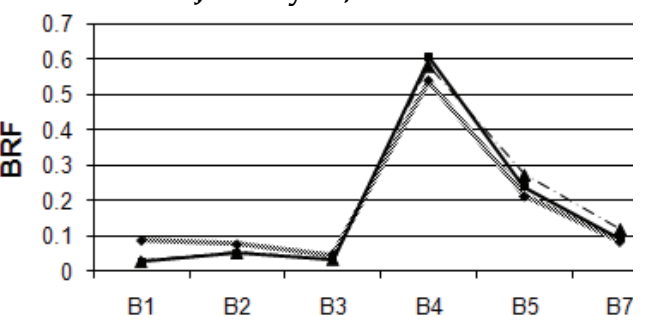

Subtitles:

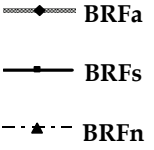

B1, B2, B3, B4, B5 e B7: TM/Landsat 5 Bands

Fig. 4. Soybeans spectral response in BRFa, BRFa and BRFn images.

As spectral data of the soybean crop were collected from the satellite images during all its cycle, it was possible to evidence the vegetation growth of the crop, mainly proven by the respective BRF of bands 4 (the near infrared strip that responds sensitively to the vegetation strength) in each one of the image dates. One can notice clearly, in the image taken in november 23, 2004, that the BRF in band 4 was approximately 0.30 at the beginning of the crop development, reaching the maximum on january, 26, 2005, with an BRF of approximately 0.6 .

After this date, the crop possibly enters the senescence period, marked by a decrease in the BRF values in band 4, as was seen in November 02, 2005.

The spectral behavior curves of the soybean crop in the images were visually similar between the BRFs and BRFn treatments, in other words, they showed lower values, mainly in band 1, in relation to the BRFa and raised the value of band 4 (Figure 4). However, they showed value differences in other bands for some image dates. That probably occurred due to the ditinct procedures each technique uses in order to ease the influence of atmosphere in the BRF data. 
The soybean mask for the 36 municipalities monitored is shown in Figure 5. The accuracy of the mask was evaluated considering 100 points that were randomly sampled, for each municipality, by using the Global Accuracy metrics and the Kappa Index (Cohen, 1960).
$54^{\circ}$ 河
$53^{\circ}$ W
$52^{\circ}$ 的

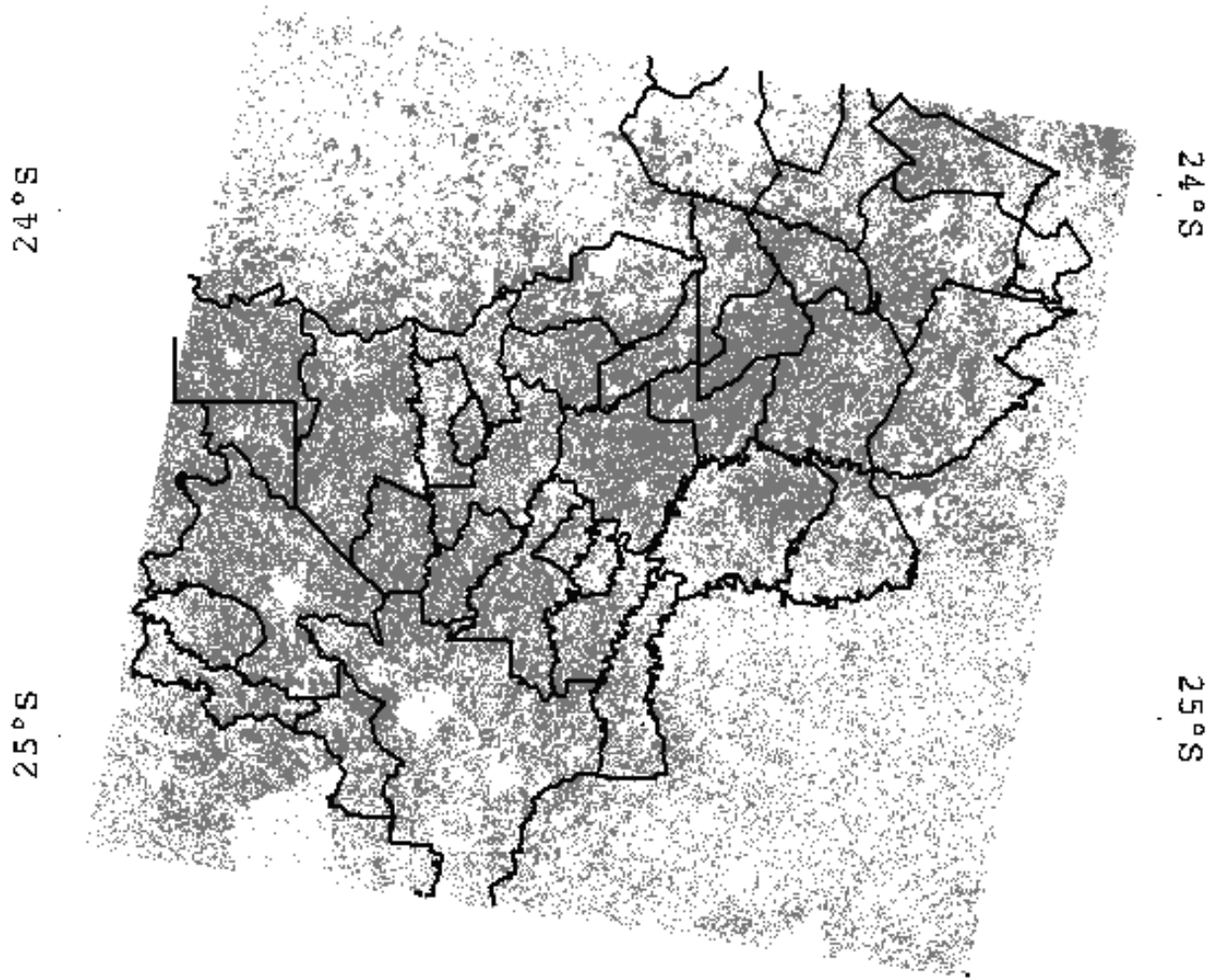

$54^{\circ} \mathrm{N}$

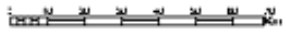

$53^{\circ}$.

Soybeans

Municipal Boundary $52^{\circ}$ ㄴ.

\section{N}

Fig. 5. Soybean mask generated with the TM/Landsat 5 images for the 2004/2005 cropping season

The Global Accuracy data varied from 0.65 to 0.95 , with an average of 0.87 . The Kappa Index data showed an average of 0.82 with variation between 0.63 and 0.92 . The Kappa Index values obtained for each municipality are above 0.63 , therefore being considered very good according to the classification presented by Landis and Koch (1977).

Descriptive statistical analysis and comparative tests of the average NDVI and GVI vegetation indexes were performed for every TM image dates. The results of these analyses for the 36 municipalities are shown on Table 2. The mean comparison ( $\mathrm{T}$ test) was accomplished among the data obtained from the BRFa, BRFs and BRFn treatments yielding NDVIa, NDVIs, NDVI n, GVIa, GVIs and GVIn according their treatment. 
The results show that in most of the dates, the indexes means were different, except for the images of january 26, 2005 (NDVI BRFa and NDVI BRFn treatments) and november 02, 2005 (for the NDVI and also to the GVI BRFs and BRFn treatments). The CV values were always below $20 \%$, given that, most of time, they were less than $15 \%$, indicating an average homogeneity in the spectral values, according to Gomes' classification (2000).

\begin{tabular}{|c|c|c|c|c|c|c|c|c|}
\hline Date & IV & Treatment & Mean & $\begin{array}{l}\text { Stand. } \\
\text { Dev. }\end{array}$ & CV (\%) & Min & Max & p-value \\
\hline \multirow{4}{*}{$\begin{array}{c}\text { November } \\
23,2004\end{array}$} & \multirow{2}{*}{ NDVI } & NDVIa(BRFa) & $0.30218 \mathbf{b}$ & 0.04 & 13.24 & 0.23372 & 0.38398 & 0.01 \\
\hline & & NDVIs(BRFs) & $0.34626 \mathbf{a}$ & 0.04 & 11.55 & 0.26093 & 0.43336 & $0.05^{*}$ \\
\hline & \multirow{2}{*}{ GVI } & GVIa(BRFa) & $0.05367 \mathbf{b}$ & 0.01 & 18.63 & 0.02958 & 0.08366 & 0.01 \\
\hline & & GVIs(BRFs) & $0.07893 \mathbf{a}$ & 0.01 & 12.67 & 0.05132 & 0.11862 & $0.05^{*}$ \\
\hline \multirow{6}{*}{$\begin{array}{c}\text { December 9, } \\
2004\end{array}$} & \multirow{3}{*}{ NDVI } & NDVIa(BRFa) & $0.43835 \mathrm{c}$ & 0.07 & 15.97 & 0.33850 & 0.60306 & 0.02 \\
\hline & & NDVIs(BRFs) & $0.48657 \mathbf{b}$ & 0.08 & 16.44 & 0.35959 & 0.65474 & 0.03 \\
\hline & & NDVIn(BRFn) & $0.64575 \mathbf{a}$ & 0.05 & 7.74 & 0.52707 & 0.76843 & $0.23^{*}$ \\
\hline & \multirow{3}{*}{ GVI } & GVIa(BRFa) & $0.11930 \mathrm{c}$ & 0.03 & 25.15 & 0.08718 & 0.19314 & 0.01 \\
\hline & & GVIs(BRFs) & $0.15099 \mathbf{b}$ & 0.03 & 19.87 & 0.09931 & 0.23562 & 0.01 \\
\hline & & GVIn(BRFn) & $0.20084 \mathbf{a}$ & 0.02 & 9.96 & 0.16629 & 0.26397 & 0.02 \\
\hline \multirow{6}{*}{$\begin{array}{c}\text { December } 25 \text {, } \\
2004\end{array}$} & \multirow{3}{*}{ NDVI } & NDVIa( BRFa) & $0.63303 \mathrm{c}$ & 0.04 & 6.32 & 0.55725 & 0.69559 & $0.07^{*}$ \\
\hline & & NDVIs(BRFs) & $0.67891 \mathbf{b}$ & 0.04 & 5.89 & 0.59490 & 0.78056 & $0.16^{*}$ \\
\hline & & NDVIn(BRFn) & $0.75329 \mathbf{a}$ & 0.03 & 3.98 & 0.68551 & 0.80041 & 0.02 \\
\hline & \multirow{3}{*}{ GVI } & GVIa(BRFa) & $0.20843 \mathrm{c}$ & 0.02 & 9.60 & 0.17161 & 0.25521 & $0.17^{*}$ \\
\hline & & GVIs(BRFs) & $0.23633 \mathbf{b}$ & 0.02 & 8.46 & 0.19784 & 0.28316 & $0.15^{*}$ \\
\hline & & GVIn(BRFn) & $0.26645 \mathbf{a}$ & 0.02 & 7.51 & 0.22822 & 0.32012 & $0.24^{*}$ \\
\hline \multirow{6}{*}{$\begin{array}{c}\text { January 26, } \\
2005\end{array}$} & \multirow{3}{*}{ NDVI } & NDVIa(BRFa) & $0.74656 \mathbf{b}$ & 0.04 & 5.36 & 0.66534 & 0.81439 & $0.08^{*}$ \\
\hline & & NDVIs(BRFs) & $0.79807 \mathbf{a}$ & 0.04 & 5.01 & 0.69274 & 0.87496 & $0.11^{*}$ \\
\hline & & NDVIn(BRFn) & $0.79832 \mathbf{a}$ & 0.03 & 3.76 & 0.73680 & 0.85154 & $0.33^{*}$ \\
\hline & \multirow{3}{*}{ GVI } & GVIa(BRFa) & $0.27990 \mathrm{c}$ & 0.03 & 10.72 & 0.22500 & 0.32444 & $0.33^{*}$ \\
\hline & & GVIs(BRFs) & $0.33481 \mathbf{a}$ & 0.03 & 8.96 & 0.25751 & 0.37990 & $0.08^{*}$ \\
\hline & & GVIn( BRFn) & $0.30767 \mathbf{b}$ & 0.02 & 6.50 & 0.25394 & 0.34649 & $0.12^{*}$ \\
\hline \multirow{6}{*}{$\begin{array}{l}\text { February 11, } \\
2005\end{array}$} & \multirow{3}{*}{ NDVI } & NDVIa(BRFa) & $0.72212 \mathbf{b}$ & 0.05 & 6.92 & 0.58936 & 0.79675 & $0.08^{*}$ \\
\hline & & NDVIs(BRFs) & $0.78336 \mathbf{a}$ & 0.05 & 6.38 & 0.65685 & 0.86127 & $0.12^{*}$ \\
\hline & & NDVIn(BRFn) & $0.77842 \mathbf{a}$ & 0.05 & 6.42 & 0.65677 & 0.85603 & $0.05^{*}$ \\
\hline & \multirow{3}{*}{ GVI } & GVIa(BRFa) & $0.24313 \mathbf{b}$ & 0.03 & 12.34 & 0.18071 & 0.29108 & $0.34^{*}$ \\
\hline & & GVIs(BRFs) & $0.29524 \mathbf{a}$ & 0.03 & 10.16 & 0.23238 & 0.34917 & $0.38^{*}$ \\
\hline & & GVIn(BRFn) & $0.27842 \mathbf{a}$ & 0.02 & 7.18 & 0.21156 & 0.32959 & $0.39 *$ \\
\hline
\end{tabular}

- For each Vegetation Index and for each image data, the measurements followed by the same letter do not differ statistically among themselves according to the T test, with a $5 \%$ significance level. ${ }^{*}$ with normal probability distribution characteristics according to the Anderson-Darling test with a 5\% significance level.

Table 2. Descriptive statistical and comparative tests for the means NDVI and GVI data. 
One can also see that Table 2 did not present the data with normality characteristics and its distribution in the NDVIa and GVIa, in the dates of of november 23, 2004 and december 09, 2004, as well as NDVIs and GVIs , from december 09, 2004, NDVIn from december 25, 2004 and GVIn from december 09, 2004. In all dates, the atmospheric correction (BRFs) and the normalization (BRFn) increased the average values of the vegetation indexes NDVI and GVI in relation to the NDVIa and GVIa.

Figures 6 and 7 correspond to the spectral profiles indicated by the temporal variation of the vegetation indexes NDVI and GVI, by using these, in general, it was possible to follow the entire crop development cycle, however, it was not possible to verify the definition of the beginning and end of the cycle, due to the restriction on the number and the image dates during the crop cycle. It was not possible either to verify if the vegetative peak occurred in the image taken on january 10,2005 , by the fact that this image was totally covered by clouds. Thus, it was not possible to observe if the vegetation indexes NDVI and GVI saturated. On the other hand, it was possible to identify the differences in the plantation among the municipalities.

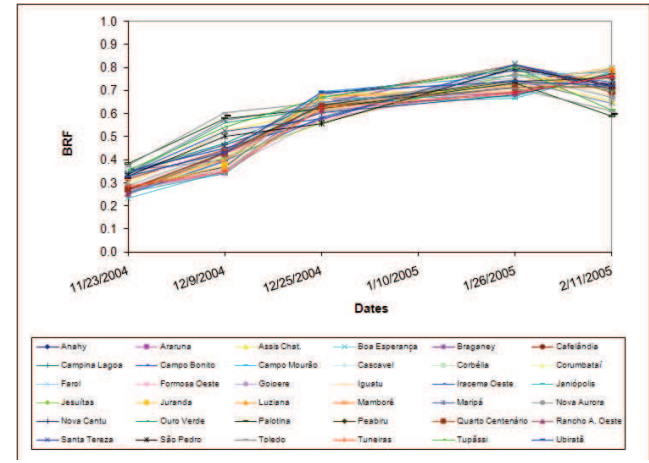

Fig. 6a. Spectral profile NDVIa.

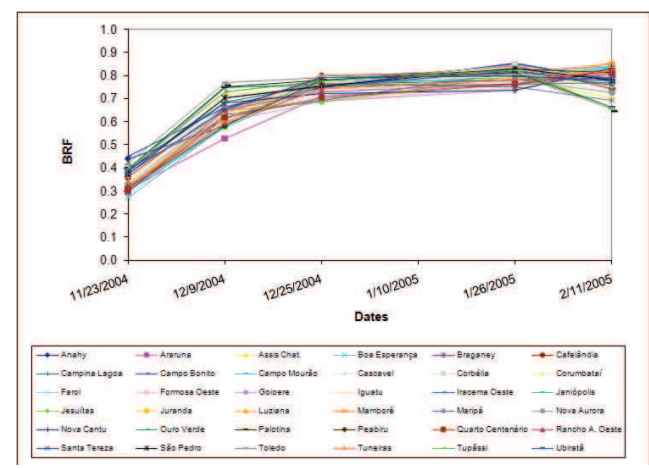

Fig. 6c. Spectral profile NDVIn.

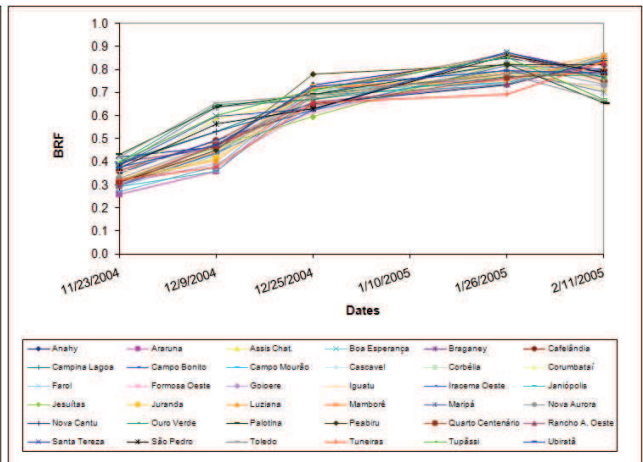

Fig. 6b. Spectral profile NDVIs.

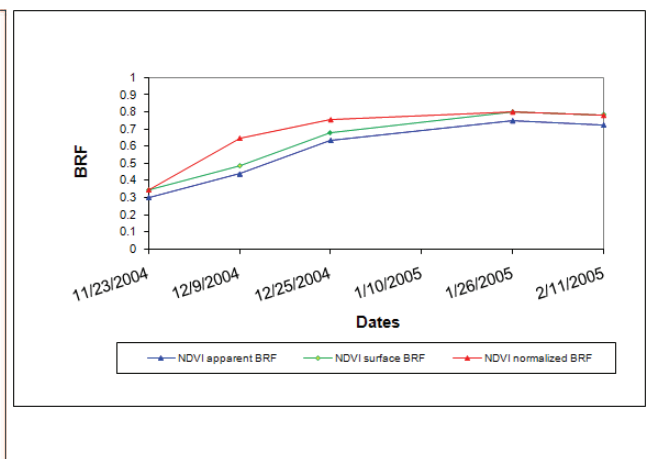

Fig. 6d. Spectral profile of the average NDVIa, NDVIs and NDVIn values for the 36 municipalities. 
Figures $6 \mathrm{a}, 6 \mathrm{~b}$ and $6 \mathrm{c}$ show the spectral profiles of the soybean crop, represented by the NDVI index of the 36 municipalities in the 2004/2005 cropping season for the BRFa, BRFs and BRFn. It was evidenced that some municipalities have delayed crop development cycles, as shown in the graphs of Figures $6 a, 6 b$ and $6 c$, in which it can be observed that some of the 36 municipalities show higher values in the date of january 26, 2005 and others in the date of february 02, 2005 (delayed cycle).

The average values of the 36 municipalities in each date for the NDVIa, NDVIs and NDVIn are shown in Figure $6 \mathrm{~d}$. By comparing them, one can observe that the NDVIn values are higher in the dates of december 09, 2004 and december 12, 2004 than the NDVIa and NDVIs. However, in the dates of january 26, 2005 and february 11, 2005, they have higher values than the NDVIa, but they are equal or lower than the NDVIs values.

The increase in the NDVIs values in relation to the NDVIa values can be explained by the influence of the atmosphere on bands 3 and 4 (Zullo Jr., 1994). The increase in the NDVIn values in relation to NDVIa and NDVIs occurs due to the use of the base or reference image with the atmosphere correction to perform the normalizing technique. It is supposed that in the image from december 12, 2004, the NDVIn showed higher values than the NDVIs (Figure 6c), probably because the atmosphere influenced less than in the date of november 23, 2004, which was used as reference for the normalization of all the other image dates, increasing the NDVIn value.

The greater NDVI average values presented by the spectral profiles were around 0.74 for the NDVIa and 0.79 for the NDVIs and NDVIn in the date of january 26, 2005, provoking a curve mischaracterization, mainly in the beginning of the crop growth, when it is compared to the spectral curve originated from the images corrected by the radiative model.

The spectral profiles of the soybean crop growth represented by the GVIa, GVIs and GVIn index for the 36 municipalities are shown in Figures 7a, 7b and 7c. As in the NDVI index, with the GVI it was possible to follow the entire development cycle, noticing differences in the plantation dates among the municipalities.

The curves of the average values of the spectral profile of the 36 municipalities for the GVIa, GVIs and GVIn are shown in Figure 7d. The GVI index also presented fairly higher values for the GVIn in relation to the GVIa and GVIs in december 09, 2004 and december 25, 2004. However, it showed higher values for the GVIs in the dates of january 26, 2005 and february 02, 2005 in relation to the GVIn and GVIa. The different values presented among the GVIa, GVIs and GVIn were higher for the normalized images, but they showed minor differences among themselves than those presented in the NDVI curves. The greater average values for the GVI fit around 0.27 for the GVIa, 0.33 for the GVIs and 0.30 for the GVIn, in the date of january 26, 2005.

Overall, by using the spectral-temporal profiles, one can observe a potential to follow the soybean development crop growth, opening way to estimate the soybean plantation and harvest dates for any given region or municipality, depending on the number of images and dates.

By comparing the spectral-temporal profiles of the NDVI and GVI indexes, one can notice that the NDVI visually presented a higher value amplitude among the municipalities in each one of the image dates, possibly because the NDVI uses only the red and the near infrared bands, and it can be considered as more sensitive to the variations of the development of 
plants (vegetation growth). Thus, the 36 municipalities, for having different crop plantation dates, have variations among them all along the growing stage of the crop, leading to higher amplitudes of the NDVI index values. The NDVI suffered higher impact with the normalization, as shown in Figures $6 \mathrm{a}, 6 \mathrm{~b}$ and $6 \mathrm{c}$. The curve had a displacement, showing higher values in the first dates of the cycle.

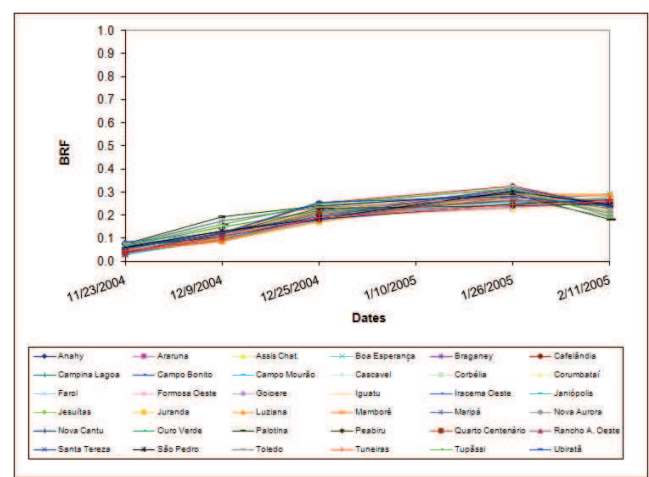

Fig. 7a. Spectral profile GVIa.

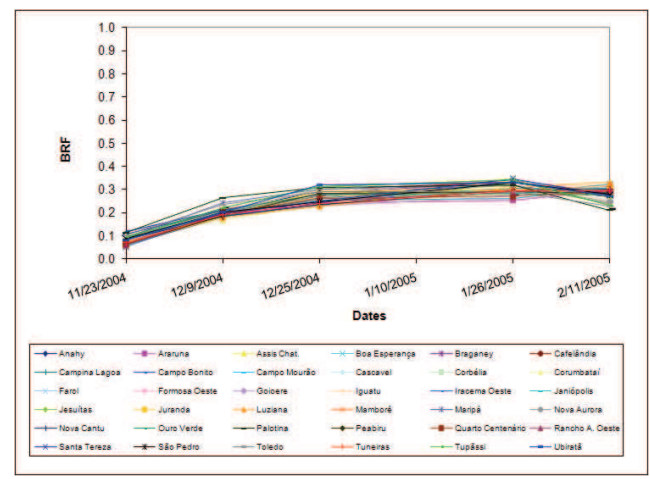

Fig. 7c. Spectral profile GVIn.

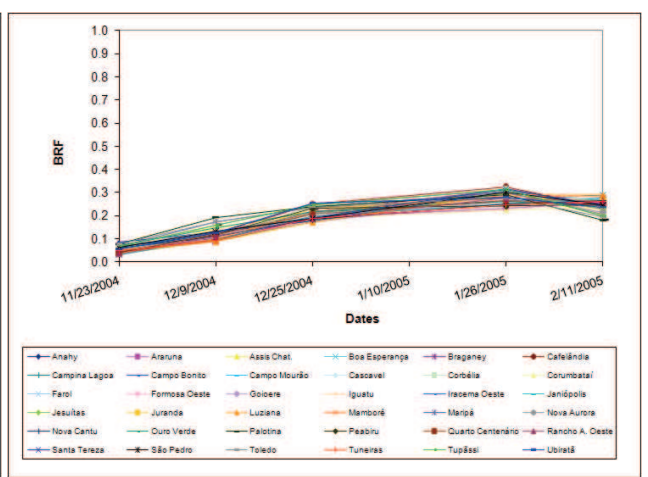

Fig. 7b. Spectral profile GVIs.

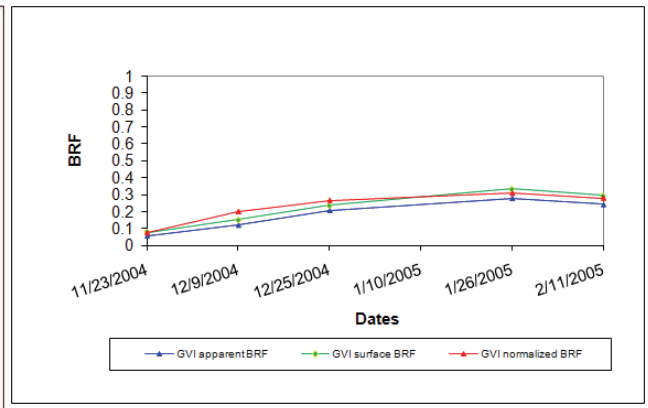

Fig. 7d. Spectral profile of the average values of vegetation index for GVI a, GVIs and GVIn for the 36 municipalities.

To better understand this behavior, spectral-temporal curves were generated in the monitored 57 ha area, with a known soybean variety, the CD-216, planted on october 16, 2004. 
Figure 8 shows the spectral-temporal profiles for the 57 ha area, according to the NDVIa, NDVIs and NDVIn index. One can verify in the spectral-temporal profiles a gradual increase in the NDVI values of november 23, 2004 until january 26, 2005, when the crop reaches its vegetative peak (highest NDVI value). It is observed that after this date the soybean crop enters the senescence period, marked by loss in the NDVI values.

By comparing the three image treatments (apparent, surface and normalized BRF), which originated the NDVI index values, one can notice the same tendency, in other words, a value increase and the index decrease in the senescence stage for the three graphs. However, the NDVIn curve is presented with higher values for the dates of december 09, 2004 and december 25, 2004, markedly changing the spectral curve in relation to the NDVIa and NDVIs values.

Figure $8 \mathrm{~b}$ shows the spectral-temporal profiles for the 57 ha area, according to the GVI index for the apparent, surface and normalized BRF. The marked increase in the GVI values from the date of november 23, 2004 until january 26, 2005, when the crop reaches its vegetative peak in the image, is also verified in the spectral profiles.
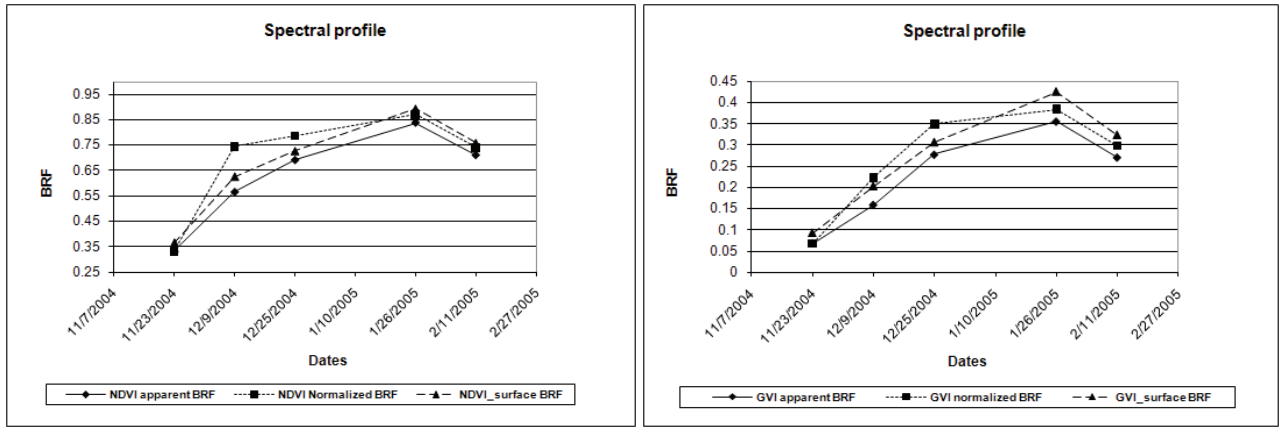

Fig. 8a. Spectral-temporal profile in the monitored area, represented by the vegetation index NDVI (BRFa, BRFs and BRFn).
Fig. 8b. Spectral-temporal profile in the monitored area, represented by the vegetation index GVI (BRFa, BRFs and BRFn).

The senescence stage happens next, marked by loss in the GVI index values.

In analogy to the NDVI vegetation index, the GVI index showed a more accentuated profile line, both for the vegetative growth of the plant, that occurred until january 26 , 2005, and for the senescence period characterized after this date. The three image treatments (apparent, surface and normalized BRF) which originated the GVI indexes once again presented the same tendency. Also, the curve of the GVIn showed higher values on december 09, 2004 and december 25, 2004, changing the form of its spectral curve in relation to the others.

One can notice that the crop stops growing after the full formation of the beans, reached in the approximate date of february 02,2005 , behaving according to its characteristics, but the spectral curves of the monitored variety showed that the normalization harmfully affected the spectral behavior of the crop. 
By comparing the spectral curves of the three types of BRF (apparent, surface and normalized), it becomes clear that the normalization technique increased the values of the profiles for all dates, mainly for the dates of december 09, 2004 and december 25, 2004, modifying the spectral curve of this cultivated soybean variety. One can suppose that the normalization an act in a more striking manner, in a negative way, in short cycle crops, and as the target has a more stable profile and a longer cycle, the impact will be minor. El Hajj (2008) offers subsidies in this sense, because he obtained good results among the spectral values calculated by normalization and with those calculated with correction by radiative transfer models for the sugar cane crop.

\section{Conclusions and suggestions}

With the implementation of the atmospheric correction and of the TM/Landsat 5 image normalization technique and, thereafter, with the finding that the obtained results for the surface and normalized BRF were presented as coherent, they become viable for the accomplishment of spectral profile analysis translated by the vegetation indexes (NDVI and GVI).

In the elapse of the crop monitoring, it was possible to map the areas with soybean, based on the images from the temporal series of the Landsat 5/TM satellite, for the 2004/2005 cropping season, generating the so called "soybean mask". However, the methodology used showed some difficult aspects, such as the time demanded for the identification of the soybean areas, by means of the generation of the supervised classification.

An alternative to ease these difficulties in similar studies is the use of spectral mixture or Fuzzy logic techniques, which may bring more refined results in the quantification of areas with soybean crop. Despite the obstacles found, the generated soybean mask was very useful in the delimitation of the representative soybean areas as reference to the creation of temporal profiles of the NDVI and GVI indexes of the Landsat 5/TM in the 36 municipalities monitored.

By means of the graphs built from the NDVI and GVI spectral profiles, it was possible to follow the soybean crop development cycle. This follow-up was done both in the monitored agriculture areas ( $57 \mathrm{ha}$ ) and in a municipal level, in the 36 monitored municipalities.

The spectral behavior of the soybean crop proved to be different for the TM/Landsat 5 images, in the comparison to different treatments BRFa, BRFs and BRFn.

The atmospheric correction (BRFs) and the implemented image normalization technique (BRFn) increased the absolute average values of the vegetation indexes in relation to the BRFa (top-of-atmosphere). It was also proven that between these two techniques, atmospheric correction and normalization, the results were statiscally different most of the time.

The normalization provoked a negative impact in the spectral-temporal curves, mischaracterizing the spectral behavior of the crop. Perhaps the normalization is less striking for targets having a softer spectral-temporal profile, such as forests or agricultural targets with a longer cycle.

The NDVI and GVI spectral average profiles made it possible to follow the soybean crop development cycle. It was also possible to observe that the BRFn mischaracterized the 
soybean crop spectral curve, mainly for the NDVI index among the stage of vegetation growth in the date of $12 / 09 / 2004$.

It is also greatly important to obtain the largest number possible of images for studies involving the temporal follow-up of agricultural crops, from plantation until harvest, diagnosing any occurrence that may harm the crop development.

Perhaps, by means of this finding, the importance of the use of sensor data with high temporal resolution was evidenced, because in the event of the TM sensor that was used, there was a limitation of data in a certain period of the crop development by the presence of clouds in the image.

Despite the fact that the study has been performed only for one of the regions with the highest production of soybean in Brazil, and with only one crop, one can see, by the obtained results, an objective manner of helping the governmental agencies to gather official, less onerous and more reliable agricultural statistics, that offer a minor data subjectivity.

\section{References}

Anderson, G.P.; Chetwynd, J.H.; Theriault, J.-M.; Acharya, P.; Berk, A.; Robertson, D.C.; Kneizys, F.X.; Hoke, M.L.; Abreu, L.W.; Shettle, E.P. (1993). MODTRAN2: suitability for remote sensing. In Proceedings of SPIE - The International Society for Optical Engineering, Orlando, FL, USA, p. 514-525.

Canty, M. J.; Nielsen, A. A.; Schmidt, M. (2004).Automatic radiometric normalization of multitemporal satellite imagery. Remote Sensing of Environment, New York, v.91, p.441 - 451.

Chander, G.; Markham, B. (2003). Revised landsat 5/tm radiometric calibration procedures and postcalibration dynamic ranges. IEEE Transactions on Geosciense and Remote Sensing. New York, v.41, n.11, p.2764-2677.

Cohen, J. A Coefficient of Agreement for Nominal Scales. Educational and Psychological Measurement. v. 20, n. 1, p. 37-46, 1960.

Coodetec - Cooperativa Central de Pesquisa Agrícola. Atividades de pesquisa - Soja. NET, Cascavel, jan.2007. Disponível em:< http://www.coodetec.com.br/ > Acesso em Fevereiro de 2007.

Crist, E.P. (1985). A TM tasseled cap equivalent transformation for reflectance factor data. Remote Sensing of Environment, New York, v.95, n 17, p.301-306.

Du, Y., Teillet, P. M. and Cihlar, J. (2002). Radiometric normalization of multitemporal highresolution images with quality control for land cover change detection. Remote Sens. Environ., 82:123-134.

El Hajj M., Bégué A., Lafrance B., Hagolle O., Dedieu G. and Rumeau M. (2008). Relative Radiometric normalization and Atmospheric Correction of a SPOT 5 Time Series. Sensors 8: 2774-2791.

Eastman, J.R. Idrisi Kilimanjaro - (2003). Guide to GIS and Image Processing. Clark Laboratory. Clark Labs, Clark university, Worcester/MA. USA. 328p.

Gomes, F. P. (2000). Curso de estatística experimental. 14 Edição. Piracicaba: ESALQ, 477 p.

Hall, F. G., Botkin, D. B., Strebel, D. E., Woods, K. D., \& Goetz, S. J. (1991). Large-scale patterns of forest succession as determined by remote sensing. Ecology, 72(2), p. 628-640. 
Kauth, R.J.; Thomas G. S. (1976). The tasseled cap - A graphic description of the spectral-temporal development of agricultural crops as seen by Landsat. In. Proc. The Symposium on Machine Processing of Remotely Sensed Data, Purdue University, West Lafayette, Indiana, p. 41-50.

Landis, J.r.; Koch, G. G. (1977). The measurement of observer agreement for categorical data. Biometrics, v. 33, n. 1, p. 159-174.

Mahmoud El Hajj ,Agnès Bégué , Bruno Lafrance, Olivier Hagolle , Gérard Dedieu and Matthieu Rumeau. (2008). Relative Radiometric Normalization and Atmospheric Correction of a SPOT 5 Time Series. Sensors, 8, p. 2774-2791.

Mercante E. (2007). Dinâmica Espectral da Cultura da Soja ao Longo do Ciclo Vegetativo e sua Relação com a Produtividade na Região Oeste do Paraná. PhD Thesis. Agricultural Engineering School, University of Campinas, Campinas. 221p.

Mercante, E.; Lamparelli, R. A. C.; Uribe-Opazo, M. A. e Rocha, J. V. (2009). Características espectrais da soja ao longo do ciclo vegetativo com imagens landsat 5/TM em área agrícola no oeste do Paraná. Engenharia Agrícola [online]. vol.29, n.2, pp. 328-338. ISSN 0100-6916. doi: 10.1590/S0100-69162009000200016.

Mercante, E.; Lamparelli, R. A. C.; Uribe-Opazo, M. A. e Rocha, J. V. (2010). Modelos de regressão lineares para estimativa de produtividade da soja no oeste do Paraná, utilizando dados espectrais. Engenharia Agrícola [online]. vol.30, n.3, pp. 504-517. ISSN 0100-6916. doi: 10.1590/S0100-69162010000300014

Moreira, R. C. (2000). Influência do posicionamento e da largura de bandas de sensores remotos e dos efeitos atmosféricos na determinação de índices de vegetação. Dissertação (Mestrado em Sensoriamento Remoto). Instituto de Pesquisas Espaciais, São José dos Campos. $114 \mathrm{p}$.

Nielsen, A.A.; Conradsen, K.; Simpson, J.J. (1998). Multivariate Alteration Detection (MAD) and MAF Post-Processing in Multispectral, Bi-temporal Image Data: New Approaches to Change Detection Studies. Remote Sensing of Environment, 64, 119.

Rouse, J. W.; Haas, R. H.; Schell, J. A.; Deering, D. W. (1973). Monitoring vegetation systems in the great plains with ERTS. In: Earth Resources Technology Satellite-1 Symposium, 3., Washington, D. C., 1973. Proceedings. Washington, D. C.: NASA. Goddart Space Flight Center, v. 1, p. 309- 317. (NASA SP-351).

Schott Jr, Salvaggio C.; Volchok, W. J. (1988). Radiometric scene normalization using pseudo invariant features. Remote Sensing of Environment, 26, 1-16.

Schroeder, T. A.; Cohen, W. B.; Song, C.; Canty, M. J.; Yang, Z. (2006). Radiometric correction of multi-temporal Landsat data for characterization of early successional forest patterns in western Oregon. Remote Sensing of Environment, v 103 , p. 16-26.

Sulsoft. Guia do ENVI em Português. Version 4.0. NET, November 2006. Available at:<http:/ / www.envi.com.br/> Accessed in February 2007.

Tanre, D. (1990). Description of a computer code to simulate the satellite signal in the solar spectrum: the 5S code. International Journal of Remote Sensing, 11, 659-668.

Teillet, P.M.; Fedosejevs, G. (1995). On the dark target approach to atmospheric correction of remotely sensed data. Canadian Journal of Remote Sensing, 21, 374-387. 
Vermote, E.F.; Tanre, D.; Deuze, J.L.; Herman, M.; Morcrette, J.J. (1997). Second simulation of thesatellite signal in the solar spectrum, 6s: an overview. IEEE Transactions on Geoscience andRemote Sensing, 35, 675-686.

Zullo Jr, J. (1994). Correção atmosférica de imagens de satélite e aplicações. Thesis (PhD in Electrical Engineering) - Electrical Engineering School, University of Campinas, Campinas, $189 \mathrm{p}$. 


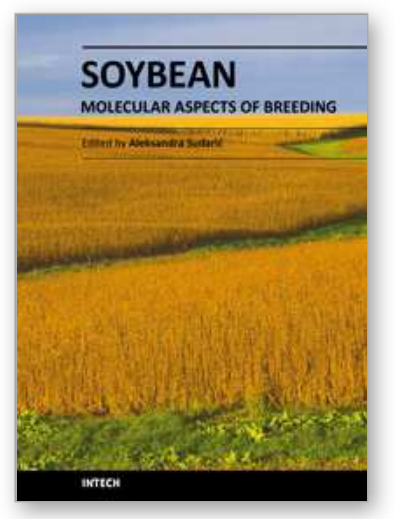

\author{
Soybean - Molecular Aspects of Breeding \\ Edited by Dr. Aleksandra Sudaric
}

ISBN 978-953-307-240-1

Hard cover, 514 pages

Publisher InTech

Published online 11, April, 2011

Published in print edition April, 2011

The book Soybean: Molecular Aspects of Breeding focuses on recent progress in our understanding of the genetics and molecular biology of soybean and provides a broad review of the subject, from genome diversity to transformation and integration of desired genes using current technologies. This book is divided into four parts (Molecular Biology and Biotechnology, Breeding for Abiotic Stress, Breeding for Biotic Stress, Recent Technology) and contains 22 chapters.

\title{
How to reference
}

In order to correctly reference this scholarly work, feel free to copy and paste the following:

Erivelto Mercante, Rubens A. C. Lamparelli, Miguel A. Uribe-Opazo and Jansle Viera Rocha (2011). Spectral Characteristics of Soybean during the Vegetative Cycle Using Landsat 5/TM Images in The Western Paraná, Brazil, Soybean - Molecular Aspects of Breeding, Dr. Aleksandra Sudaric (Ed.), ISBN: 978-953-307-240-1, InTech, Available from: http://www.intechopen.com/books/soybean-molecular-aspects-of-breeding/spectralcharacteristics-of-soybean-during-the-vegetative-cycle-using-landsat-5-tm-images-in-the-wes

\section{INTECH}

open science | open minds

\section{InTech Europe}

University Campus STeP Ri

Slavka Krautzeka 83/A

51000 Rijeka, Croatia

Phone: +385 (51) 770447

Fax: +385 (51) 686166

www.intechopen.com

\section{InTech China}

Unit 405, Office Block, Hotel Equatorial Shanghai

No.65, Yan An Road (West), Shanghai, 200040, China

中国上海市延安西路65号上海国际贵都大饭店办公楼 405 单元

Phone: +86-21-62489820

Fax: $+86-21-62489821$ 
(C) 2011 The Author(s). Licensee IntechOpen. This chapter is distributed under the terms of the Creative Commons Attribution-NonCommercialShareAlike-3.0 License, which permits use, distribution and reproduction for non-commercial purposes, provided the original is properly cited and derivative works building on this content are distributed under the same license. 